\title{
DNA Damage Response Assessments in Human Tumor Samples Provide Functional Biomarkers of Radiosensitivity
}

Henning Willers, MD, ${ }^{1}$ Liliana Gheorghiu, MS, ${ }^{1}$ Qi Liu, PhD, ${ }^{1}$ Jason A. Efstathiou, MD, DPhil, ${ }^{1}$ Lori J. Wirth, MD, ${ }^{2}$ Mechthild Krause, MD, ${ }^{3,4,5,6}$, and Cläre von Neubeck, $\mathrm{PhD}^{3,5}$

${ }^{1}$ Department of Radiation Oncology and ${ }^{2}$ Department of Medicine, Massachusetts General Hospital, Boston, Massachusetts, USA; ${ }^{3}$ Germany Cancer Consortium (DKTK) Dresden and German Cancer Research Center (DKFZ), Heidelberg, ${ }^{4}$ Department of Radiation Oncology, Faculty of Medicine and University Hospital Carl Gustav Carus, Technische Universität Dresden, ${ }^{5}$ OncoRay - National Center for Radiation Research in Oncology, Faculty of Medicine and University Hospital Carl Gustav Carus, Technische Universität Dresden, ${ }^{6}$ Helmholtz-Zentrum Dresden - Rossendorf, Institute of Radiooncology; Germany.

Corresponding Author: Henning Willers, M.D., Dept. of Radiation Oncology, Massachusetts General Hospital, 55 Fruit Street, Boston, MA 02114. Tel.617-726-5184, Email: hwillers@mgh.harvard.edu

Abstract: 223 words

Text: 7,604 words

References: 129

Figures: 4

Tables: 1 


\section{Abstract}

Predictive biomarkers are urgently needed for individualization of radiation therapy and treatment with radiosensitizing anti-cancer agents. Genomic profiling of human cancers will provide us with unprecedented insight into the mutational landscape of genes directly or indirectly involved in the response to radiation-induced DNA damage. However, to what extent this wealth of structural information about the cancer genome will produce biomarkers of sensitivity to radiation remains to be seen. Investigators are increasingly studying the subnuclear accumulation (i.e., foci) of proteins in the DNA damage response (DDR), such as $\gamma-\mathrm{H} 2 \mathrm{AX}, 53 \mathrm{BP} 1$, or RAD51, as a surrogate of treatment sensitivity. Recent findings from preclinical studies have demonstrated the predictive potential of DDR foci by correlating foci with clinically relevant endpoints such as tumor control probability. Therefore, pre-clinical investigations of DDR foci responses are increasingly moving into cells and tissues from patients, which is the major focus of this review. The advantage of using DDR foci as functional biomarkers is that they can detect alterations in DNA repair due to various mechanisms. Moreover, they provide a global measurement of DDR network function without needing to know the identities of all the components, many of which remain unknown. Foci assays are thus expected to yield functional insight that may complement or supersede genomic information, thereby giving radiation oncologists unique opportunities to individualize cancer treatments in the near future. 


\section{Introduction}

It is evident that cancer patients display a wide range of treatment sensitivities with regard to both tumor and normal tissue responses. Predictive biomarkers are urgently needed for individualization of radiation therapy and DNA damaging systemic therapies, which includes chemotherapeutics, therapeutic antibodies, and molecularly targeted drugs such as poly(ADPribose)polymerase (PARP) inhibitors. Following exposure to ionizing radiation (IR) and many drugs, DNA double-strand breaks (DSBs) represent the principal lesion which, if not adequately repaired, can lead to cell death via the generation of lethal chromosomal aberrations or other mechanisms (reviewed in ref. ${ }^{1}$ ). Alternatively, an inaccurately repaired or unrepaired DSB may result in mutations or genomic rearrangements in a surviving cell, thereby promoting genomic instability and malignant cell transformation. Complex DNA damage response (DRR) pathways have evolved, and are evolutionarily conserved, to protect the cell from the potentially deleterious effects of a DSB. Two principle pathways, homologous recombination repair (HRR) and non-homologous end-joining (NHEJ), remove DSBs by employing separate as well as overlapping protein complexes.

There is increasing evidence from functional studies and recent genomic analyses that alterations of DNA repair exist in human tumors that may impact treatment sensitivities ${ }^{2-8}$. Therefore, identification of alterations in the DDR following DSB induction would be very useful for individualization of treatments. Possible treatment modifications include (de-)escalation of radiation dose or combining radiation therapy with targeted drugs that further exploit pre-existing DNA repair defects. It is possible that whole genome sequencing will ultimately provide us with sufficient information on the overall state of DSB repair in a given tumor to inform treatment approaches that produce DSBs. However, it is also possible, and in our opinion more likely, that genomic information will be in most cases insufficient to predict how tumors will respond to therapeutic DSBs (with some exceptions such as predicted synthetic lethality resulting from BRCA mutations and PARP inhibition ${ }^{9}$ ). 
Many investigators now believe that a functional assessment of the DDR in human tumor tissues can be used to predict treatment sensitivities ${ }^{2,4,5,8}$. Such functional assays most often rely on the detection of subnuclear foci of DDR proteins (reviewed in ref. ${ }^{10}$ ). Foci represent multiprotein complexes that are organized into centers surrounding a DSB and can be visualized as "dots" using immunofluorescence microscopy in cells and tissues (Figure 1A). These complexes are highly dynamic structures in order to coordinate DNA repair and checkpoint responses. Many DDR proteins shuttle transiently in and out of the focus, or are degraded at the damage site. The composition of these repair centers depends on the type of DNA damage and the cell cycle phase of the damaged cell. The regulation of its components is ensured through complex post-transcriptional modifications and other mechanisms. The accumulation of DDR factors around a DSB is thought to serve multiple purposes including sheltering the broken DNA ends from decay, preventing undesired repair from occurring, and promoting chromatin relaxation to facilitate access of repair proteins. The increased concentration of many DDR proteins around the damage site likely stimulates their activities and results in an amplification of the DNA damage signal. Foci may also serve as a "toolbox" in which DDR proteins assemble to promote different repair pathways ${ }^{10}$.

There exists a vast literature on foci responses in established cell lines and a considerably smaller but emerging body of data on conducting foci assays on tissues and cells from patients ${ }^{4,5,8,11-14}$. The focus of the current review is to provide an overview of the opportunities as well as technical challenges associated with the use of patient samples. The reader is also referred to a number of recent reviews on this and related topics ${ }^{10,15-19}$. Overall, the analysis of DDR foci in patient-derived samples is feasible and reliable but correlations of foci data with clinical outcomes are urgently needed.

\section{DDR Foci Endpoints: $\gamma-\mathrm{H} 2 \mathrm{AX}$ and 53BP1}

One of the earliest events in the DDR is the rapid phosphorylation of the histone variant $\mathrm{H} 2 \mathrm{AX}$ at serine 139 , four residues from its carboxyl terminus, in the vicinity of the DSB by members of the phosphatidylinositol 3-kinase family, i.e., Ataxia Telangiectasia Mutated (ATM), AT and Rad3-related 
(ATR), and DNA-dependent protein kinase (DNA-PK) ${ }^{20-23} \cdot \mathrm{H} 2 \mathrm{AX}$ is one of the most conserved H2Avariants, and within the $\mathrm{H} 2 \mathrm{~A}$ pool, the fraction of $\mathrm{H} 2 \mathrm{AX}$ levels varies between 2 and $25 \%{ }^{20}$. Upon DSB induction, $\gamma-\mathrm{H} 2 \mathrm{AX}$, the phosphorylated form of $\mathrm{H} 2 \mathrm{AX}$, appears as subnuclear foci within minutes and reaches a maximum after approximately 30 minutes $^{24}$. Gamma-H2AX is dephosphorylated and foci disperse reflecting DSB repair ${ }^{24,25}$. Although many repair proteins form distinct foci, $\gamma-\mathrm{H} 2 \mathrm{AX}$ foci have the important feature to be a new protein species induced by physical DSB formation and are formed throughout all cell cycle phases ${ }^{26}$. Recent studies have shown that NHEJ is the predominant pathway in the G1- and G2-phase of the cell cycle while HRR repairs only $15-20 \%$ of the DSBs in late S- and G2phase ${ }^{26}$. Residual foci which are detectable for more than 24 hours after IR likely represent misrepaired or incompletely repaired lethal DSBs ${ }^{27}$. Thus residual $\gamma-\mathrm{H} 2 \mathrm{AX}$ foci may be a useful surrogate of cellular radiosensitivity. Accordingly, for a variety of cell lines and for a broad range of IR doses, a linear correlation of the number of residual $\gamma-\mathrm{H} 2 \mathrm{AX}$ foci with cell survival has been shown in most studies ${ }^{27-31}$. Even for the low but clinically relevant dose of 2 Gy the correlation seems to hold although at this dose the assay may only be able to identify the most radiosensitive tumors (Figure 1B). With appropriate assay modifications, the clinical value of residual $\gamma-\mathrm{H} 2 \mathrm{AX}$ will also lie in the prediction of radioresistance and in the prediction of radiosensitization caused by a molecular targeted agent. This is illustrated in Figure 1C, D where the addition of a heat shock protein 90 inhibitor clearly increases the number of residual $\gamma-\mathrm{H} 2 \mathrm{AX}$ foci in some head and neck squamous cell carcinoma (HNSCC) cell lines which correlates with the ability of this agent to radiosensitize cells. In fact, a large number of molecularly targeted agents may radiosensitize through modulation of DSB repair as Table 1 illustrates ${ }^{32-53}$. If this were to hold true in tumor biopsies from patients, $\gamma-\mathrm{H} 2 \mathrm{AX}$ could be a very useful biomarker to guide the clinical administration of radiosensitizing targeted drugs.

Gamma-H2AX can be quantified by Western blotting, flow cytometry analysis, or by enumerating discrete foci using microscopy ${ }^{15}$. Although flow cytometry has the advantage of fast and high sample throughput, microscopy is the most sensitive method for $\gamma-\mathrm{H} 2 \mathrm{AX}$ foci detection and, 
therefore, is the predominant technique of $\gamma-\mathrm{H} 2 \mathrm{AX}$ detection in current pre-clinical applications ${ }^{19,54,55}$. Specifically in patient samples, several additional reasons account for microscopy as the method of choice to detect $\gamma-\mathrm{H} 2 \mathrm{AX}$ foci: i) detection of individual DSB marked by foci, ii) heterogeneous responses in tumor tissue (e.g. oxic or hypoxic regions), iii) discrimination between foci from tumor cells or surrounding normal tissue, and iv) the degree of DNA damage (e.g. pan-staining in apoptotic, mitotic or necrotic cells, diffuse foci in S-phase cells).

The tumor suppressor TP53 binding protein 1 (53BP1) is an alternative marker for visualization of IR-induced DSBs ${ }^{56}$ (Figure 1E, Table 1). Accumulating evidence suggests that it is located upstream in the DDR and involved in regulation of both HRR and NHEJ ${ }^{57,58}$. Potentially, it is more specific for marking DSB than $\gamma-\mathrm{H} 2 \mathrm{AX}$ which also stains areas of DNA not containing a DSB and apoptotic nuclei ${ }^{59,60}$. However, more comparative studies of $\gamma-\mathrm{H} 2 \mathrm{AX}$ and 53BP1 in human samples are needed ${ }^{61,62}$.

Lastly, an imaging probe capable of revealing DSB in-vivo could provide useful information regarding treatment response and bypass the technical difficulties surrounding microscopy-based foci analysis on biopsy specimens as is further discussed below. The high abundance of $\gamma-\mathrm{H} 2 \mathrm{AX}$ expression in tumor cells is most likely sufficient for molecular imaging. Cornelissen et al. ${ }^{63}$ developed a radioimmunoconjugate that targets $\gamma-\mathrm{H} 2 \mathrm{AX},{ }^{111} \mathrm{In}-\mathrm{DTPA}$-anti- $\gamma \mathrm{H} 2 \mathrm{AX}-\mathrm{Tat}$, and is able to penetrate the cell and its nucleus. The radioimmunoconjugate was used to visualize radiation-induced accumulation of $\gamma-\mathrm{H} 2 \mathrm{AX}$ with in-vivo fluorescence imaging and single photon emission computed tomography in a heterotopic breast cancer model. Although the probe warrants further validation such as dose response correlations, in-vivo imaging holds the promise of a non-invasive imaging tool for detecting treatmentinduced DSBs in preclinical and clinical settings.

\section{DDR Foci Endpoints: Focus on HRR}

Of the two principal DSB repair pathways, NHEJ and HRR, the latter is more readily assayed owing to the nature of many HRR proteins to form visible foci. Foci of the main HRR recombinase, 
RAD51, form in response to stalled/collapsed DNA replication forks or DSBs in the S- or G2-phase of the cell cycle (reviewed in ref ${ }^{10}$ ). RAD51 foci are commonly used as a surrogate measure of local HRR activity based on genetic analysis and reporter substrate studies ${ }^{64-66}$. The proper formation of RAD51 foci is controlled by a multitude of proteins, including BRCA2, RAD52, PALB2, and BRCA1, but also upstream regulators such as ATR or ATM. Thus, genetic or epigenetic defects anywhere in the HRR pathway can lead to an impairment or even complete abrogation of RAD51 foci formation. However, which defects in the Fanconi Anemia (FA) pathway impair FANCD2/BRCA2 function to compromise RAD51 foci formation remains controversial ${ }^{4,67-71}$. Some of the conflicting data may be related to variations in the type of DNA damage signal used and the ambiguity of what to consider a HRR "proficient" versus "deficient" cell. In addition, FA pathway defects are expected to only affect foci formation in S-phase, so that normal RAD51 foci formation in G2-phase can potentially mask any foci alterations in S-phase in an asynchronous cell population. This highlights the general need to assess cell cycle distributions and cell cycle specificity of RAD51 foci formation when conducting these studies.

BRCA1 and RAD51 co-localize in S-phase foci, consistent with a functional relationship between these two proteins ${ }^{72}$. BRCA1 foci are present in undamaged S-phase cells where they may be involved in processing stalled replication forks due to endogenous DNA damage. Following induction of exogenous DNA damage, these foci disperse and relocate at exogenous damage sites that contain RAD51 $1^{73}$. The recruitment of BRCA1 into foci is complex and involves several protein complexes with functions that extend beyond HRR control (reviewed in ref. ${ }^{74}$ ). Mutations in the $B R C A 1$ gene will disrupt BRCA1 foci formation and impair RAD51 foci formation, while alterations in directly or functionally interacting proteins, such as MDC1, may attenuate the induction of BRCA1 foci in response to DNA damage $e^{75,76}$

The recruitment of FANCD2 into subnuclear foci is dependent upon mono-ubiquitination by the FA core complex as well as BRCA1 function ${ }^{69}$. To which extent FANCD2 is involved in the promotion of HRR remains poorly defined ${ }^{77,78}$. One role of FANCD2 in foci may be to facilitate HRR needed for replication fork restart ${ }^{79,80}$. Thus, attenuated or absent FANCD2 foci are expected to predict sensitivity 
to a variety of DNA damaging agents including $\mathrm{IR}^{81}$. For clinical application, a challenge is to determine what exactly constitutes an attenuated FANCD2 (or BRCA1 or RAD51) foci response to DNA damage without knowing the normal kinetics of foci formation and the normal range of foci per nucleus across a range of different cancer cell lines and cancer tissues (see also below).

Even though HRR proteins such as RAD51, BRCA1, and FANCD2 are relatively straightforward to measure by cell-based microscopic analysis, it is quite possible that HRR defects do not contribute significantly to clinical radiosensitivity because NHEJ is the dominant pathway for the repair of IRinduced DSB in human cells ${ }^{1}$. At a minimum, knowledge of HRR defects would be very useful for the selection of concurrent systemic therapies, including cisplatin or PARP inhibitors, which should yield at least additive tumor toxicity ${ }^{10}$. NHEJ proteins in contrast do not form discernible foci in cells (reviewed in ref. ${ }^{17}$ ). This is likely due to high baseline expression in the nucleus and a requirement for a smaller number of molecules at the DSB site compared to HRR proteins. Phosphorylation of DNA-PKcs is required for NHEJ and can be detected as foci, but whether this can be used as a surrogate for NHEJ proficiency remains unknown ${ }^{82}$.

\section{Requirement for a DNA Damage Signal to Induce Foci}

It is obvious that measurement of therapeutic DSBs using $\gamma-\mathrm{H} 2 \mathrm{AX}$ or 53BP1 foci requires preceding exposure to DNA damaging agents. It is also important to appreciate that the activity of the HRR pathway is similarly dependent on the ability to localize these proteins into foci, in order to coordinate and execute repair, but less dependent on protein expression levels ${ }^{10}$. For example, even in the presence of hypomorphic mutations in the HRR pathway BRCA1 and RAD51 foci may be visible in S- or G2-phase cells and the fraction of cells with foci and the number of foci per cells may increase post-irradiation ${ }^{65,83,84}$. In contrast, completely BRCA1-deficient cells have an impaired ability to mount FANCD2 and RAD51 foci responses ${ }^{65,69}$. This is illustrated in Figure 2A where BRCA1-mutant MDAMB-436 breast cancer cells cannot mount any RAD51 foci response even though the nuclear expression level is normal. H1937 cells, which express a hypomorphic BRCA1 mutation, have retained 
the ability to induce RAD51 foci. This functional difference is associated with a pronounced difference in sensitivity to mitomycin C (Figure 2B). This illustrates the importance of "functional biomarker" analysis (i.e., RAD51 foci) rather than assessment of "biomarker expression" (RAD51 expression).

Thus, the functional status of HRR (as an example of the DDR in general) is typically revealed only when cells are exposed to DNA damage. It should be possible to use the ability of cells to form DDR foci as a functional biomarker of the integrity of the DDR network, and vice versa interpret the absence of repair foci induction, coupled with a persistence of DSB markers $\gamma-\mathrm{H} 2 \mathrm{AX}$ or/and 53BP1, as an indicator of treatment sensitivity. This is illustrated in Figure 2C.

\section{DDR Foci Assays on Human Samples}

Administration of radiation therapy with or without radiosensitizing agents will induce DNA damage not only in the tumor but also in the normal tissues. Although measurement of DDR foci is well established in in-vitro cell cultures, methods to translate these assays into patient-derived samples remain highly experimental. Assessing the foci response in live tumors would require a repeat biopsy following initial administration of treatment. Not only is such an approach limited to cancers that are easily accessible for a needle biopsy, such as head and neck, breast, extremity sarcoma, or cervix cancers, personalization of therapy may be difficult after it has been already initiated. DDR foci can also be assessed in circulating tumor cells (CTCs) or peripheral blood lymphocytes (PBL). The most promising alternative is the use of pre-treatment biopsies. Such samples can be interrogated for their ability to form DDR foci in order to select the appropriate treatment regimen for a given patient. This requires some form of ex-vivo approach to expose tumor tissues or other samples to DNA damage in the laboratory.

Several groups have used ex-vivo assays in recent years to monitor DDR foci responses following treatment with IR or drugs $4,5,8,13,14,85$. This approach is based on the idea that tumor tissues can remain viable for several days if cultured properly following removal from the patient. The use of organotypic slice cultures is a method long established in the field of neurological science and only recently 
expanded to the study of cancers ${ }^{86-89}$. Vaira et al. ${ }^{89}$ established organotypical cultures from a variety of previously untreated epithelial cancers. Slices of 300-500 $\mu \mathrm{m}$ were cut from surgical samples with a vibratome and cultured on organotypical inserts to preserve the three-dimensional (3D) tissue architecture. Cell viability assays, gene expression profiling, and assessment of PI3K/AKT activity validated the ex-vivo culture approach for up to five days following removal from the patient.

Our own approach has been driven by the desire to obtain rapid read outs of treatment sensitivity using needle biopsies that can ultimately inform treatment decisions in real time ${ }^{13,90}$ (Figure 3 ). In brief, core biopsy materials are obtained, placed in chilled complete cell culture medium with $10 \%$ serum, and equilibrated in a humidified cell culture incubator at $37^{\circ} \mathrm{C}$ and $5 \% \mathrm{CO}_{2}$. Within $60-90$ minutes after removal from the patient the specimen is divided into smaller samples and subjected to mock treatment, IR with 4-10 Gy, or drug treatments, depending on the amount of tissue available ${ }^{13}$. Following ex-vivo treatments, samples continue incubation for 5-48 hours depending on the particular experiment to allow for DDR foci formation. In cases where we do not extend incubation beyond $\sim 24$ hours we do not add antibiotics or antifungals to the medium. However, this may be considered when the microbial burden in the tumor specimen is high due to tumor location in the mouth or intestine. Samples are then snap-frozen in OCT (Optimal Cutting Temperature) for later analysis. Formalin fixation and paraffin embedding (FFPE) of samples is an alternative and economical long-term preservation method. Serial sections of approximately 4-5 microns are obtained. Every fifth section may be subjected to hematoxylin/eosin (H\&E) staining for confirmation of viable tumor cells. The other slides are stained with specific antibodies for visualization of DDR foci and counterstained with DAPI for visualization of nuclei using immunofluorescence microscopy. Additional stains can be performed and are discussed below. Typically 8-10 random high-power (100x) images are obtained from at least two slides in order to count at least 200-400 tumor nuclei for each experimental condition (and up to $\sim 1,000$ depending on the particular experiment and presence of intra-tumoral heterogeneity).

Using the above approach, we conducted a pilot study in which core biopsies from seven women with previously untreated, locally advanced breast cancers (without BRCA1/2 mutations) were 
subjected to $8 \mathrm{~Gy}$ irradiation or mock treatment ex-vivo ${ }^{13}$. RAD51, BRCA2, and FANCD2 foci could be readily visualized in individual irradiated cells from three tumors with an intact foci response, while the other four tumors lacked foci induction. Yet, there was no difference in the baseline of foci numbers in non-irradiated tumor cells. Notably, three of the four foci-defective tumors were "triple-negative", a phenotype associated with BRCA1 deficiency. There was reduced BRCA1 expression in only two of the four foci-defective tumors. Even though the number of subjects in this study was small, these data suggested that gene expression may correlate poorly with HRR pathway activity as measured by foci formation, and further, that a functional pathway defect is only revealed upon DNA damage induction, i.e., ex-vivo treatment.

Simon Powell's group has expanded on this approach and in a preliminary analysis identified six out of 30 breast cancers lacking a RAD51/BRCA1 foci response ${ }^{85}$. Furthermore, instead of using core biopsies, an approach involving fine-needle biopsy aspirates was developed. Breast cancer aspirates were made into a cell suspension in $\sim 1 \mathrm{ml}$ of phosphate buffered saline, ex-vivo irradiated or mock treated, incubated for 4 hours, and fixed on glass slides after processing the cell suspension in a cytospin. It was felt that the staining process was generally easier compared to using intact tumor tissues, with less permeability problems and a better signal-to-noise ratio. The downside of this approach is loss of the 3D tissue architecture.

CTCs can be non-invasively isolated from the patient's blood and are therefore available for repeated measurements during treatment or for ex-vivo treatment studies. The $\gamma-\mathrm{H} 2 \mathrm{AX}$ foci assay has been performed on CTCs in several clinical trials. Increased DSBs could be measured following treatment of a variety of solid tumors with the topoisomerase I inhibitor topotecan, of advanced breast cancers with platinum-based chemotherapy, of a panel of solid tumors and lymphomas with the PARP inhibitor veliparib in combination with topotecan, and of multiple solid cancers with a combined treatment of veliparib and cyclophosphamide ${ }^{91-94}$. Although the advantages of a "liquid tumor biopsy" are obvious, the approach is limited due to technical challenges identifying CTCs, defining robust controls as well as turnaround time and costs of the isolation procedure ${ }^{95}$. Similarly, establishing 
patient-derived xenografts, primary cell cultures, or cell lines is a lengthy procedure that may not be suitable to inform real time treatment decisions.

\section{$\gamma$-H2AX Foci for Predicting the Radiosensitivity of Human Tumors}

Despite major improvements in cancer therapy for many tumor entities the overall cure rates are still unsatisfying and biomarkers for treatment individualization are needed ${ }^{96}$. Soon after the discovery of the crucial functions of $\gamma-\mathrm{H} 2 \mathrm{AX}$ in DSB repair it was hypothesized that the rate of $\gamma-\mathrm{H} 2 \mathrm{AX}$ foci reduction due to repair and the relative residual DNA damage after exposure to IR would be a useful indicator for the intrinsic radiosensitivity of cells. A more rapid foci reduction and less retention were assumed to be associated with a more radioresistant cell type ${ }^{97}$.

The possibility of using $\gamma-\mathrm{H} 2 \mathrm{AX}$ foci as a potential predictor of tumor response to treatment was first explored in cohorts of advanced carcinomas of the uterine cervix ${ }^{98,99}$. Comparison of residual (24 hours) $\gamma-\mathrm{H} 2 \mathrm{AX}$ foci in 47 untreated and eight radiation/chemotherapy patients revealed that only $25 \%$ of tumor nuclei exhibited $\gamma-\mathrm{H} 2 \mathrm{AX}$ foci before treatment and $74 \%$ after the start of treatment ${ }^{98}$. Preand post-treatment biopsies from 26 patients showed an increased percentage of tumor cells containing $\gamma-\mathrm{H} 2 \mathrm{AX}$ foci after therapy (i.e., $24+/-19 \%$ and $38+/-19 \%$, respectively). Although small differences in delivered dose (1.8 vs. $2.5 \mathrm{~Gy}$ ) could be quantified, local tumor control was unrelated to the fraction of cells that retained $\gamma-\mathrm{H} 2 \mathrm{AX}$ foci ${ }^{99}$. This study illustrates the difficulty of quantifying foci responses on post-treatment biopsy materials.

More than $50 \%$ of HNSCC patients with advanced stage disease develop a recurrence after primary radiation/chemotherapy, which in the majority of cases is not curable ${ }^{100}$. Identification of patients with therapy-resistant tumors would potentially allow for early treatment adaptation and hold the promise of increased cure rates. In nine xenografted human HNSCC models, $\gamma-\mathrm{H} 2 \mathrm{AX}$ foci were correlated with the necessary dose to control $50 \%$ of those tumors locally $\left(\operatorname{TCD}_{50}\right)^{2,101,102}$. Foci evaluated 30 minutes or 24 hours after in-vivo irradiation were significantly correlated with $\operatorname{TCD}_{50}$ 
values but residual foci were found to be a more robust marker for local control. In contrast to the above mentioned patient study, foci evaluation was performed here under consideration of the tumor oxygenation, a factor that critically impacts the IR-induced number of $\gamma$-H2AX foci in-vivo ${ }^{2,97,101}$. Valid results for parameters of the tumor micromilieu can be gained in pre-treatment core needle biopsies, although accuracy is somewhat limited by intra-tumoral heterogeneity ${ }^{103}$. The number of $\gamma-\mathrm{H} 2 \mathrm{AX}$ foci invivo decreases linearly with increasing distance from the perfused vasculature ${ }^{101}$. Constant $\gamma-\mathrm{H} 2 \mathrm{AX}$ foci values can be evaluated in viable, oxic tumor cells with a maximum distance of $45 \mu \mathrm{m}$ from the nearest perfused blood vessel indicated by the hypoxia marker pimonidazole and the proliferation marker BrdU ${ }^{2}$. The micromilieu-corrected evaluation of foci in-vivo was successfully translated to exvivo irradiated tumor biopsies from xenografted tumors and patient-derived specimens (Menegakis et al., unpublished).

The cancer stem cell (CSC) content and the intrinsic radiosensitivity of CSCs vary between tumors and affect their curability ${ }^{104}$. The lack of reliable markers to discriminate between CSC and nonCSC impede the development of predictive tests for the clinic to optimize and individualize radiation therapy. There is evidence that the radioresistance of CSC is associated with altered $\gamma-\mathrm{H} 2 \mathrm{AX}$ foci formation after irradiation. For example, glioblastoma cells expressing the CSC marker CD133 were shown to have fewer radiation-induced $\gamma-\mathrm{H} 2 \mathrm{AX}$ foci than their non-CD133 expressing counterparts in an orthotopic model in-vivo but not in in-vitro cultured cells. Moreover, after irradiation a growth delay of seven days was associated with increasing percentage of CD133 positive cells in-vivo ${ }^{105}$. Similar findings of reduced $\gamma-\mathrm{H} 2 \mathrm{AX}$ foci in CSC models of lung cancer have been obtained in our laboratory (Willers et al., unpublished). These data emphasize the significance of in-vivo studies and tumor cell microenvironment to perform radioresistance studies by means of CSC and $\gamma-\mathrm{H} 2 \mathrm{AX}$ foci. 
The administration of chemotherapeutics can critically influence $\gamma-\mathrm{H} 2 \mathrm{AX}$ foci results. Mumbrekar et al. reported that post-chemotherapy patients had significantly more $\gamma-\mathrm{H} 2 \mathrm{AX}$ foci in PBLs than healthy donors which was very likely an effect of the doxorubicin- and cyclophosphamide-based regimen ${ }^{106}$. This is consistent with data showing that several chemotherapeutics induce DSB either directly or indirectly ${ }^{10}$. The combined effect of IR and cisplatin on $\gamma-\mathrm{H} 2 \mathrm{AX}$ formation was analyzed in ex-vivo and in-vivo irradiated PBLs of a group of 28 cancer patients. Cisplatin treatment led to a decrease in IRinduced $\gamma-\mathrm{H} 2 \mathrm{AX}$ formation of about $30 \%$. The foci variability was greater from patient to patient than for repeated measures within a patient ${ }^{107}$. Another commonly used agent, 5-fluorouracil (5-FU), is converted to the active metabolites fluorodeoxyuridine triphosphate and fluorouridine triphosphate which are incorporated into DNA and RNA. Although mechanistic details are still incomplete, base excision repair and mismatch repair seem to be the major pathways to repair 5-FU-induced DNA damage independent of DSBs ${ }^{108}$. Nonetheless, the $\gamma-\mathrm{H} 2 \mathrm{AX}$ assay seems to have the potential to predict the individual sensitivity to 5 -FU-based combination treatments ${ }^{16}$. Interestingly, after ex-vivo irradiation of PBL, the $\gamma-\mathrm{H} 2 \mathrm{AX}$ assay was very precise in terms of predicting radiosensitivity relative to

in-vivo irradiated PBL ${ }^{109}$. However, concurrently administered chemotherapeutics, especially cisplatin, limit the precision of this method for predicting radiosensitivity ${ }^{107,109}$. In contrast, as suggested in Table $1, \gamma-\mathrm{H} 2 \mathrm{AX}$ assays will likely be useful to assess combinations with radiosensitizing targeted drugs that do not increase DSB levels unless they are combined with IR.

\section{Identification of HRR Defects for Prediction of Treatment Sensitivity}

The identification of HRR-defective tumors is important for several clinical applications such as prediction of radiosensitivity (including potential hypersensitivity to proton beam radiation ${ }^{110}$ ), chemosensitivity (in particular platinum drugs), and many targeted agents (e.g., PARP inhibitors). At a minimum, this will involve assaying for key proteins such as $\gamma-\mathrm{H} 2 \mathrm{AX}$ and RAD51 foci, but ideally also additional central DDR regulators such as BRCA1, FANCD2, and others. 
Van Gent and colleagues obtained 54 fresh primary breast cancer samples from patients undergoing surgery ${ }^{5}$. Organotypic slice cultures were prepared and subjected to 5 Gy irradiation. Incubation and irradiation of samples was performed within 6 hours after surgical resection. Two hours after irradiation, samples were fixed in formalin and paraffin embedded. Sections were stained for DAPI, geminin (to identify cells in S/G2-phase), and RAD51. A cell was considered positive for RAD51 foci if more than five nuclear foci were detected. Using this approach, $11 \%$ of tumors displayed a RAD51 foci defect. The foci defect was significantly associated with triple-negative breast cancer, and two of five HRR-deficient tumors did not show mutations in the BRCA genes but BRCA1 promoter hypermethylation. The authors suggested that the RAD51 foci ex-vivo assay faithfully identifies HRRdeficient tumors and has clear advantages over gene sequencing. It is a relatively easy assay that can be performed on biopsy material, making it a powerful tool to select patients with an HRR-deficient cancer for PARP inhibitor treatment in the clinic.

The authors noted that the observed $\sim 10 \%$ incidence of HRR-defective tumors was lower than prior estimates of $\sim 25 \%$ of HRR defects in sporadic breast cancers ${ }^{11-13,111}$. However, conducting the assay with IR alone at a relatively short time point (2 hours) is likely to only capture severe HRR defects due to BRCA1/2 disruption but will miss a number of other HRR defects. For example, our own in-vitro data indicate that tumor cells with an S-phase specific HRR defect, for example due to an alteration in the FA pathway, may display normal RAD51 foci induction after IR exposure but defective induction after replication-fork blocking treatments, such as cisplatin ${ }^{90}$. To detect this, a 24 -hour time point would be required.

Another study performed the RAD51 foci assay on biopsies from 68 sporadic breast cancers that were obtained 24 hours after the first cycle of anthracycline-based chemotherapy ${ }^{111}$. The authors scored RAD51 and $\gamma$-H2AX foci on FFPE tumor tissues. A geminin-positive nucleus was scored as positive if it contained at least at one RAD51 focus. A low RAD51 foci score of $<10 \%$ positive nuclei was found in $26 \%$ of cancers. In a subset analysis it was shown that low RAD51 foci scores did not reflect lack of drug effect as there was a concomitant high $\gamma-\mathrm{H} 2 \mathrm{AX}$ foci score as a marker of induced 
DSB. Interestingly, a low RAD51 foci score was seen in $67 \%$ of the twelve triple-negative cancers, compared to $19 \%$ in the other cancers, and a low RAD51 score was correlated with pathological complete response at the time of surgery. The challenge of conducting an in-vivo approach such as this includes the logistics of obtaining a biopsy during treatment and uncertainties surrounding drug concentration in the biopsied tumor area.

Interestingly, HRR defects seem to be common in a variety of epithelial tumor types with incidences that appear to be in the order of $15-25 \%$ in many cases (reviewed in ref. ${ }^{10}$ ). A similar figure was observed when we interrogated a panel of lung cancer cell lines and tissues for the ability to induce RAD51 in response to cisplatin ${ }^{4}$. Tissue samples from surgical resections were exposed to 8 $\mu \mathrm{M}$ cisplatin or IR as a control and snap frozen after 5 hours. Nuclei with at least two foci were scored as positive. It is noted in this context that there are variations between reports with regard to the number of foci per nucleus in a cross section that signifies a "positive" cell. More studies on the question as to how many foci constitute a repair-defective versus -proficient cell in tissues are needed.

Cells in S-phase were identified by staining for PCNA. Similar to the cell line data, there was a range of RAD51 foci induction with numbers lower than in cell lines, i.e., on average only $6 \%$ of cisplatin-treated cells in each tumor scored positive for RAD51 foci compared to $\sim 19 \%$ in cell lines. This lower fraction of cells with RAD51 foci in tumor tissues was explained by a several-fold lower fraction of cells in S-phase. In 15\% of tumors, very few cisplatin-induced RAD51 foci (< 1\% of cells) were seen, indicating a putative HRR defect and suggesting cisplatin sensitivity. In-vitro analysis, however, indicated that $\gamma-\mathrm{H} 2 \mathrm{AX}$ foci were actually superior to RAD51 foci in terms of predicting cell kill by cisplatin, likely because mechanisms other than loss of RAD51 function can also cause cisplatin sensitivity. In addition, HRR defects can manifest themselves not only as a failure to induce RAD51 foci but also a failure to resolve foci, presumably due to defects in resolvase proteins such as SLX4 or FAN1 ${ }^{90,110}$. Detection of this phenomenon would require more than one time point and extending tissue incubation to at least 48 hours, which may be difficult to carry out on limited amounts of biopsy 
materials. Thus, foci scores or signatures encompassing at least several DDR proteins will have to be designed to accurately assess the DDR after treatment at an early time point.

These data also indicate that anti-cancer drugs will penetrate tumor tissue samples ex-vivo and elicit a DDR as illustrated in Figure 1A and 4A. With this type of assay one can envision a rapid assessment of drug sensitivities on biopsy material ex-vivo and results reporting within a few days. This is of particular interest for current efforts to identify predictive biomarkers of PARP inhibitors which can be employed in monotherapy or in combination therapy, for example with IR. While some data suggest that IR-based ex-vivo assays will accurately predict PARP inhibitor sensitivity ${ }^{5,112}$, we are not aware of any studies that have exposed organotypic 3D cultures to PARP inhibitors. To this end, Curtin and colleagues established cell cultures from malignant pleural effusions obtained from 13 patients with various cancers ${ }^{8}$. Cultures were exposed to a PARP inhibitor, and RAD51 and $\gamma$-H2AX foci were scored, in parallel to next-generation sequencing of DNA repair genes. The authors determined that one third of cultures had a HRR defect. No mutations in DNA repair genes were associated with HRR status in this small cohort.

\section{Technical Challenges of Foci Studies in Tumor Tissues In-Vivo or Ex-Vivo}

There exist numerous but not insurmountable logistical and technical challenges with regard to functional assessment of foci responses in tumor tissues in-vivo and ex-vivo. Collection of fresh biopsy materials or other tissues for ex-vivo treatments requires considerable resources. Biopsies of tumors during treatment carry the additional issue of timing with regard to the prior treatment and potential uncertainty with regard to concentration of drug, if it was administered, within the biopsied tissue. Needle biopsies always carry the risk of not knowing whether the biopsy location is representative of the tumor as a whole. Surgical specimens obtained before initiation of therapy typically provide an ample source of tissue for analysis. However, absence of gross tumor post-surgery precludes direct correlation of therapy outcomes with the results of the ex-vivo foci assay. 
Intra- and inter-tumoral heterogeneity of foci formation within tumor specimens is of considerable concern. This is already well established for $\gamma-\mathrm{H} 2 \mathrm{AX}$ foci where it may relate to genomic instability and other factors ${ }^{99}$. Figure 1F shows immunohistochemistry images of a HNSCC sample stained for tumor cell identification (panel a) and assessment of oxygenation status (using pimonidazole) and cell viability (BrdU) (panel b). This type of co-staining is important because hypoxia can affect $\gamma-\mathrm{H} 2 \mathrm{AX}$ foci formation as well as other DSB repair pathways ${ }^{113,114}$. In this context, it is unknown how potential changes in hypoxia/reoxygenation upon removal of the tumor tissue from the patient and incubation in the laboratory at $\sim 20 \%$ oxygen will affect foci readouts. Studies to compare invivo irradiated tumors with ex-vivo irradiated biopsies are currently being conducted in Dresden to determine the possible influence of ex-vivo culturing on foci formation.

Figure 1F also illustrates that some tumors can have an increased $\gamma-\mathrm{H} 2 \mathrm{AX}$ signal at baseline, i.e., without any treatment (panel c). Elevated endogenous $\gamma-\mathrm{H} 2 \mathrm{AX}$ foci levels are suggested to be a characteristic of carcinogenesis and also are associated with tumors positive for the human papilloma virus (HPV) ${ }^{2,115,116}$. The latter is likely related to the observation that HPV-positive human HNSCC cell lines and tumors are more radiosensitive than HPV-negative cancers due to compromised DSB repair $117-119$

Similarly, foci of HRR proteins may vary considerable as they will only occur in cells that are in S- or/and G2-phase. The fraction of cells in these cell cycle phases is much lower in tissues than in established cell lines in-vitro. In addition, there can be considerable heterogeneity with regard to the presence of cycling tumor cells within a biopsy specimen. This is illustrated in Figure 4B which shows the quantification of RAD51 foci responses following ex-vivo treatment of lung cancer samples with cisplatin. In some tumors there is considerable variation of RAD51 foci counts across different parts of the sample, and in untreated tumors this variation could mask any treatment-induced foci increase. In another example, FANCD2 foci induction by IR is predicted to be S-phase specific and thus can be 
clearly heterogeneous (Figure 1G). These problems may be overcome by simply increasing the number of analyzed images or/and co-staining with S/G2 markers such as geminin or PCNA.

Occasionally it is difficult to identify tumor cells based on DAPI morphology alone, which requires additional stains such as cytokeratin or H\&E. Foci counting is labor-intensive, indicating a need for automation of foci scoring. Appropriate software applications are available for foci analysis in cell cultures but sophisticated solutions to semi-quantify foci in tumor specimens are missing ${ }^{8,120}$. However, we find that manual scoring by a trained investigator or technician is more reliable in terms of distinguishing foci from unspecific stains or artifacts, which in a tissue context are quite common. To this end, it must be emphasized that staining of tumor tissue for DDR foci requires extensive optimization especially when co-staining is involved, and antibody performance can differ quite dramatically from in-vitro experiments. Nonetheless, solid tumor specimens with preserved 3D architecture have a major advantage: they are the closest model of the actual tumor and should therefore predict the clinical treatment outcome most precisely.

\section{$\gamma-\mathrm{H} 2 \mathrm{AX}$ Assays for Biodosimetry and Prediction of Normal Tissue Toxicity}

While the focus of this review is on foci assays in tumor tissues we will also briefly address data on the value of $\gamma-\mathrm{H} 2 \mathrm{AX}$ for the measurement of IR exposure and prediction of normal tissue toxicity. Particularly the excellent correlation of $\gamma-\mathrm{H} 2 \mathrm{AX}$ foci and IR exposure doses in lymphocytes support the

promise of using $\gamma-\mathrm{H} 2 \mathrm{AX}$ in tumors ${ }^{19}$, assuming that intra- and inter-tumoral heterogeneity with regard to foci expression can be overcome.

Isolation of PBL from patient blood samples is a non-invasive method which guarantees easy access of biomaterial and repeated measures during treatment. These liquid biopsies are widely used in biodosimetry to estimate the delivered dose to an exposed individual ${ }^{121}$. For example, the analysis of $\gamma-\mathrm{H} 2 \mathrm{AX}$ foci in PBL from a group of cancer patients 30 minutes after in-vivo irradiation showed a linear dependency of $\gamma-\mathrm{H} 2 \mathrm{AX}$ foci formation and mean body dose. The steepness of the foci dose response 
curve for PBLs increased with the partial blood volume of the irradiated organ limiting the applicability and precision for individual prediction of applied mean dose ${ }^{122}$.

The $\gamma-\mathrm{H} 2 \mathrm{AX}$ foci assay also has been used on ex-vivo irradiated blood lymphocytes as a clinical biomarker to identify small subsets of patients at risk of severe normal tissue toxicity. Microscopic foci analysis was confirmed as the method of choice by comparing three different methods (foci, comet, and neutral filtration assay) to detect a $\gamma$-H2AX signal in ex-vivo irradiated (2 Gy) PBLs from 54 HNSCC patients receiving radiation/chemotherapy. The foci assay could best detect a correlation of $\gamma-\mathrm{H} 2 \mathrm{AX}$ signal and acute oral mucositis and dermatitis (grade $\geq 3)^{123}$. In two studies with 41 and 47 pediatric solid tumors and leukemia patients receiving DNA-damaging therapy, $\gamma-\mathrm{H} 2 \mathrm{AX}$ foci were evaluated in ex-vivo irradiated PBL which enabled the identification of patients at risk for high-grade acute and late toxicities and allowed for detection of DSB repair deficiencies, although not all treatment-associated normal-tissue toxicities could be explained by DSB repair insufficiencies ${ }^{124,125}$. Similar observations were made with regard to severe late effects in prostate cancer patients and acute (grade $\geq 2$ ) dermatitis in breast cancer patients ${ }^{106,126}$. In contrast to these findings, a number of studies which also used blood lymphocytes for $\gamma-\mathrm{H} 2 \mathrm{AX}$ evaluation could not find a correlation with acute side effects $109,127,128$. However, caution must be taken with the interpretation of these results. None of the above studies was randomized, all were performed at single institutes, and the recruited patient numbers are generally low.

\section{Conclusions}

Over the next few years, genomic profiling of human cancers will provide us with unprecedented insight into the mutational landscape of genes directly or indirectly involved in the DDR. However, to what extent this wealth of structural information about the cancer genome will reveal biomarkers of radiosensitivity and radiosensitization by anti-cancer agents remains to be seen. The concept of highly ordered and regulated protein machineries at the DSB has profound implications for the development of 
biomarkers to predict the functional status of DSB repair in a given cancer. Even if the entire genome and epigenome of a cancer was deciphered, a lack of in-depth knowledge of the functional interactions of DDR gene products and other regulatory components would complicate predictions of DSB repair proficiency and cellular sensitivity to anti-cancer agents including IR. These considerations stress the value of functional DDR assays that can provide a measure of DSB repair without needing to fully understand the functional consequences of all genomic alterations.

The advantage of using DDR foci as functional biomarkers is that they can detect repair defects due to several mechanisms such as gene mutations, epigenetic events, or alterations in signal transduction pathways which are increasingly recognized as modulating DDR ${ }^{10}$. Moreover, they provide a global measurement of DDR network function without needing to know the identities of all the components, many of which are still unknown. One can envision developing mechanism-based "DDR foci signatures" that reflect nodal points in the network. Such signatures may include $\gamma-H 2 A X, 53 B P 1$, BRCA1, FANCD2, RAD51, and other proteins. Research into monitoring these foci responses is now increasingly moving into cells and tissues from patients which should produce functional insight that can complement or supersede genomic information, thereby giving radiation oncologists unique opportunities to individualize cancer treatments. 


\section{Acknowledgements}

In part supported by Dana-Farber/Harvard Cancer Center SPORE in Lung Cancer, NCI P50 CA090578 (HW), American Cancer Society 123420RSG-12-224-01-DMC (HW), Department of Defense W81XWH-06-1-0309 (HW), Susan G. Komen for the Cure of Breast Cancer BCTR0504040 (HW), Federal Share of program income earned by Massachusetts General Hospital on C06 CA059267, Proton Therapy Research and Treatment Center (JAE, HW). LJW and HW wish to thank 


\section{References}

1. Willers H, Dahm-Daphi J, Powell SN. Repair of radiation damage to DNA. British Journal of Cancer 2004;90(7):1297-301.

2. Koch U, Höhne K, von Neubeck C, Thames HD, Yaromina A, Dahm-Daphi J, Baumann M, Krause M. Residual gammaH2AX foci predict local tumour control after radiotherapy. Radiother Oncol 2013;108(3):434-9.

3. Ding L, Getz G, Wheeler DA, Mardis ER, McLellan MD, Cibulskis K, Sougnez C, Greulich H, Muzny DM, Morgan MB and others. Somatic mutations affect key pathways in lung adenocarcinoma. Nature 2008;455(7216):1069-75.

4. Birkelbach M, Ferraiolo N, Gheorghiu L, Pfäffle HN, Daly B, Ebright M, Spencer c, O'Hara C, Whetstine JR, Benes $\mathrm{CH}$ and others. Detection of Impaired Homologous Recombination Repair in NSCLC Cells and Tissues. J Thorac Oncol 2013;8:279-86.

5. Naipal KA, Verkaik NS, Ameziane N, van Deurzen CH, Ter Brugge P, Meijers M, Sieuwerts AM, Martens JW, O'Connor MJ, Vrieling $\mathrm{H}$ and others. Functional Ex Vivo Assay to Select Homologous Recombination-Deficient Breast Tumors for PARP Inhibitor Treatment. Clin Cancer Res 2014;20(18):4816-26.

6. Yap KL, Kiyotani K, Tamura K, Antic T, Jang M, Montoya M, Campanile A, Yew PY, Ganshert C, Fujioka $T$ and others. Whole-Exome Sequencing of Muscle-Invasive Bladder Cancer Identifies Recurrent Mutations of UNC5C and Prognostic Importance of DNA Repair Gene Mutations on Survival. Clin Cancer Res 2014;20(24):6605-17.

7. Alexander BM, Wang XZ, Niemierko A, Weaver DT, Mak RH, Roof KS, Fidias P, Wain J, Choi NC. DNA repair biomarkers predict response to neoadjuvant chemoradiotherapy in esophageal cancer. Int J Radiat Oncol Biol Phys 2011;83(1):164-71.

8. Patterson MJ, Sutton RE, Forrest I, Sharrock R, Lane M, Kaufmann A, O'Donnell R, Edmondson RJ, Wilson BT, Curtin NJ. Assessing the function of homologous recombination DNA repair in malignant pleural effusion (MPE) samples. Br J Cancer 2014;111(1):94-100.

9. Lord CJ, Tutt AN, Ashworth A. Synthetic Lethality and Cancer Therapy: Lessons Learned from the Development of PARP Inhibitors. Annu Rev Med 2015;66:455-70.

10. Willers H, Pfäffle HN, Zou L. Targeting Homologous Recombination Repair in Cancer. Kelley MR, editor: Academic Press, Elsevier; 2012. 119-160 p. 
11. Asakawa H, Koizumi H, Koike A, Takahashi M, Wu W, Iwase H, Fukuda M, Ohta T. Prediction of breast cancer sensitivity to neoadjuvant chemotherapy based on status of DNA damage repair proteins. Breast Cancer Res 2010;12(2):R17.

12. Turner N, Tutt A, Ashworth A. Hallmarks of 'BRCAness' in sporadic cancers. Nat Rev Cancer 2004;4(10):814-9.

13. Willers H, Taghian AG, Luo C-M, Treszezamsky AD, Sgroi D, Powell SN. Utility of DNA repair protein foci for the detection of putative BRCA1-pathway defects in breast cancer biopsies. Mol Cancer Res 2009;7:1304-1309.

14. Mukhopadhyay A, Elattar A, Cerbinskaite A, Wilkinson SJ, Drew Y, Kyle S, Los G, Hostomsky Z, Edmondson RJ, Curtin NJ. Development of a functional assay for homologous recombination status in primary cultures of epithelial ovarian tumor and correlation with sensitivity to poly(ADPribose) polymerase inhibitors. Clin Cancer Res 2010;16(8):2344-51.

15. Goodarzi AA, Jeggo PA. Irradiation induced foci (IRIF) as a biomarker for radiosensitivity. Mutat Res 2012;736(1-2):39-47.

16. Sak A, Stuschke M. Use of gammaH2AX and other biomarkers of double-strand breaks during radiotherapy. Semin Radiat Oncol 2010;20(4):223-31.

17. Vignard J, Mirey G, Salles B. Ionizing-radiation induced DNA double-strand breaks: a direct and indirect lighting up. Radiother Oncol 2013;108(3):362-9.

18. Jalal S, Earley JN, Turchi JJ. DNA repair: from genome maintenance to biomarker and therapeutic target. Clin Cancer Res 2011;17(22):6973-84.

19. Ivashkevich A, Redon CE, Nakamura AJ, Martin RF, Martin OA. Use of the gamma-H2AX assay to monitor DNA damage and repair in translational cancer research. Cancer Lett 2012;327(12):123-33.

20. Rogakou EP, Pilch DR, Orr AH, Ivanova VS, Bonner WM. DNA double-stranded breaks induce histone H2AX phosphorylation on serine 139. J Biol Chem 1998;273(10):5858-68.

21. Burma S, Chen BP, Murphy M, Kurimasa A, Chen DJ. ATM phosphorylates histone H2AX in response to DNA double-strand breaks. J Biol Chem 2001;276(45):42462-7.

22. Park EJ, Chan DW, Park JH, Oettinger MA, Kwon J. DNA-PK is activated by nucleosomes and phosphorylates $\mathrm{H} 2 \mathrm{AX}$ within the nucleosomes in an acetylation-dependent manner. Nucleic Acids Res 2003;31(23):6819-27.

23. Ward IM, Chen J. Histone H2AX is phosphorylated in an ATR-dependent manner in response to replicational stress. J Biol Chem 2001;276(51):47759-62.

24. Rogakou EP, Boon C, Redon C, Bonner WM. Megabase chromatin domains involved in DNA double-strand breaks in vivo. J Cell Biol 1999;146(5):905-16. 
25. Leatherbarrow EL, Harper JV, Cucinotta FA, O'Neill P. Induction and quantification of gammaH2AX foci following low and high LET-irradiation. Int J Radiat Biol 2006;82(2):111-8.

26. Nakamura AJ, Rao VA, Pommier Y, Bonner WM. The complexity of phosphorylated H2AX foci formation and DNA repair assembly at DNA double-strand breaks. Cell Cycle 2010;9(2):389-97.

27. Klokov D, MacPhail SM, Banath JP, Byrne JP, Olive PL. Phosphorylated histone H2AX in relation to cell survival in tumor cells and xenografts exposed to single and fractionated doses of X-rays. Radiother Oncol 2006;80(2):223-9.

28. Menegakis A, Yaromina A, Eicheler W, Dorfler A, Beuthien-Baumann B, Thames HD, Baumann $M$, Krause M. Prediction of clonogenic cell survival curves based on the number of residual DNA double strand breaks measured by gammaH2AX staining. Int J Radiat Biol 2009;85(11):1032-41.

29. Rothkamm K, Lobrich M. Evidence for a lack of DNA double-strand break repair in human cells exposed to very low x-ray doses. Proc Natl Acad Sci U S A 2003;100(9):5057-62.

30. Kunogi H, Sakanishi T, Sueyoshi N, Sasai K. Prediction of radiosensitivity using phosphorylation of histone H2AX and apoptosis in human tumor cell lines. Int J Radiat Biol 2014;90(7):587-93.

31. Mahrhofer H, Burger S, Oppitz U, Flentje M, Djuzenova CS. Radiation induced DNA damage and damage repair in human tumor and fibroblast cell lines assessed by histone $H 2 A X$ phosphorylation. Int J Radiat Oncol Biol Phys 2006;64(2):573-80.

32. Toulany M, Kehlbach R, Florczak U, Sak A, Wang S, Chen J, Lobrich M, Rodemann HP. Targeting of AKT1 enhances radiation toxicity of human tumor cells by inhibiting DNA-PKcsdependent DNA double-strand break repair. Mol Cancer Ther 2008;7(7):1772-81.

33. Fasih A, Elbaz HA, Huttemann M, Konski AA, Zielske SP. Radiosensitization of pancreatic cancer cells by metformin through the AMPK pathway. Radiat Res 2014;182(1):50-9.

34. Fokas E, Prevo R, Pollard JR, Reaper PM, Charlton PA, Cornelissen B, Vallis KA, Hammond EM, Olcina MM, Gillies McKenna W and others. Targeting ATR in vivo using the novel inhibitor VE-822 results in selective sensitization of pancreatic tumors to radiation. Cell Death Dis 2012;3:e441.

35. Myllynen L, Rieckmann T, Dahm-Daphi J, Kasten-Pisula U, Petersen C, Dikomey E, Kriegs M. In tumor cells regulation of DNA double strand break repair through EGF receptor involves both NHEJ and HR and is independent of p53 and K-Ras status. Radiother Oncol 2011;101(1):147-51.

36. Wang M, Morsbach F, Sander D, Gheorghiu L, Nanda A, Benes C, Kriegs M, Krause M, Dikomey $E$, Baumann $M$ and others. EGF receptor inhibition radiosensitizes NSCLC cells by inducing senescence in cells sustaining DNA double-strand breaks. Cancer Res 2011;71(19):6261-9.

37. Hehlgans S, Storch K, Lange I, Cordes N. The novel HDAC inhibitor NDACI054 sensitizes human cancer cells to radiotherapy. Radiother Oncol 2013;109(1):126-32. 
38. Camphausen K, Burgan W, Cerra M, Oswald KA, Trepel JB, Lee MJ, Tofilon PJ. Enhanced radiation-induced cell killing and prolongation of gammaH2AX foci expression by the histone deacetylase inhibitor MS-275. Cancer Res 2004;64(1):316-21.

39. Toulany M, Minjgee M, Kehlbach R, Chen J, Baumann M, Rodemann HP. ErbB2 expression through heterodimerization with erbB1 is necessary for ionizing radiation- but not EGF-induced activation of Akt survival pathway. Radiother Oncol 2010;97(2):338-45.

40. Dote H, Burgan WE, Camphausen K, Tofilon PJ. Inhibition of hsp90 compromises the DNA damage response to radiation. Cancer Res 2006;66(18):9211-20.

41. Segawa T, Fujii Y, Tanaka A, Bando S, Okayasu R, Ohnishi K, Kubota N. Radiosensitization of human lung cancer cells by the novel purine-scaffold Hsp90 inhibitor, PU-H71. Int J Mol Med 2014;33(3):559-64.

42. Iwasa T, Okamoto I, Suzuki M, Hatashita E, Yamada Y, Fukuoka M, Ono K, Nakagawa K. Inhibition of insulin-like growth factor 1 receptor by CP-751,871 radiosensitizes non-small cell lung cancer cells. Clin Cancer Res 2009;15(16):5117-25.

43. Kriegs M, Kasten-Pisula U, Rieckmann T, Holst K, Saker J, Dahm-Daphi J, Dikomey E. The epidermal growth factor receptor modulates DNA double-strand break repair by regulating nonhomologous end-joining. DNA Repair (Amst) 2010;9(8):889-97.

44. Welsh JW, Mahadevan D, Ellsworth R, Cooke L, Bearss D, Stea B. The c-Met receptor tyrosine kinase inhibitor MP470 radiosensitizes glioblastoma cells. Radiat Oncol 2009;4:69.

45. Hayman TJ, Wahba A, Rath BH, Bae H, Kramp T, Shankavaram UT, Camphausen K, Tofilon PJ. The ATP-competitive mTOR inhibitor INK128 enhances in vitro and in vivo radiosensitivity of pancreatic carcinoma cells. Clin Cancer Res 2014;20(1):110-9.

46. Chen H, Ma Z, Vanderwaal RP, Feng Z, Gonzalez-Suarez I, Wang S, Zhang J, Roti Roti JL, Gonzalo S, Zhang J. The mTOR inhibitor rapamycin suppresses DNA double-strand break repair. Radiat Res 2011;175(2):214-24.

47. Shelton JW, Waxweiler TV, Landry J, Gao H, Xu Y, Wang L, El-Rayes B, Shu HK. In vitro and in vivo enhancement of chemoradiation using the oral PARP inhibitor ABT-888 in colorectal cancer cells. Int J Radiat Oncol Biol Phys 2013;86(3):469-76.

48. Ahnesorg P, Smith P, Jackson SP. XLF interacts with the XRCC4-DNA ligase IV complex to promote DNA nonhomologous end-joining. Cell 2006;124(2):301-13.

49. Kao GD, Jiang Z, Fernandes AM, Gupta AK, Maity A. Inhibition of phosphatidylinositol-3-OH kinase/Akt signaling impairs DNA repair in glioblastoma cells following ionizing radiation. J Biol Chem 2007;282(29):21206-12. 
50. Raju U, Riesterer O, Wang ZQ, Molkentine DP, Molkentine JM, Johnson FM, Glisson B, Milas L, Ang KK. Dasatinib, a multi-kinase inhibitor increased radiation sensitivity by interfering with nuclear localization of epidermal growth factor receptor and by blocking DNA repair pathways. Radiother Oncol 2012;105(2):241-9.

51. Zhang C, Yang X, Zhang Q, Guo Q, He J, Qin Q, Zhu H, Liu J, Zhan L, Lu J and others. STAT3 inhibitor NSC74859 radiosensitizes esophageal cancer via the downregulation of HIF-1alpha. Tumour Biol 2014;35(10):9793-9.

52. Zhang M, Kleber S, Rohrich M, Timke C, Han N, Tuettenberg J, Martin-Villalba A, Debus J, Peschke $P$, Wirkner $U$ and others. Blockade of TGF-beta signaling by the TGFbetaR-I kinase inhibitor LY2109761 enhances radiation response and prolongs survival in glioblastoma. Cancer Res 2011;71(23):7155-67.

53. PosthumaDeBoer J, Wurdinger T, Graat HC, van Beusechem VW, Helder MN, van Royen BJ, Kaspers GJ. WEE1 inhibition sensitizes osteosarcoma to radiotherapy. BMC Cancer 2011;11:156.

54. Bonner WM, Redon CE, Dickey JS, Nakamura AJ, Sedelnikova OA, Solier S, Pommier Y. GammaH2AX and cancer. Nat Rev Cancer 2008;8(12):957-67.

55. Bourton EC, Plowman PN, Smith D, Arlett CF, Parris CN. Prolonged expression of the gammaH2AX DNA repair biomarker correlates with excess acute and chronic toxicity from radiotherapy treatment. Int J Cancer 2011;129(12):2928-34.

56. Markova E, Schultz N, Belyaev IY. Kinetics and dose-response of residual 53BP1/gamma-H2AX foci: co-localization, relationship with DSB repair and clonogenic survival. Int J Radiat Biol 2007;83(5):319-29.

57. Xiong X, Du Z, Wang Y, Feng Z, Fan P, Yan C, Willers H, Zhang J. 53BP1 promotes microhomology-mediated end-joining in G1-phase cells. Nucleic Acids Res 2015;in press.

58. Kakarougkas A, Ismail A, Klement K, Goodarzi AA, Conrad S, Freire R, Shibata A, Lobrich M, Jeggo PA. Opposing roles for 53BP1 during homologous recombination. Nucleic Acids Res 2013;41(21):9719-31.

59. Solier S, Pommier $\mathrm{Y}$. The apoptotic ring: a novel entity with phosphorylated histones $\mathrm{H} 2 \mathrm{AX}$ and H2B and activated DNA damage response kinases. Cell Cycle 2009;8(12):1853-9.

60. Sirbu BM, Couch FB, Feigerle JT, Bhaskara S, Hiebert SW, Cortez D. Analysis of protein dynamics at active, stalled, and collapsed replication forks. Genes Dev 2011;25(12):1320-7.

61. Djuzenova CS, Elsner I, Katzer A, Worschech E, Distel LV, Flentje M, Polat B. Radiosensitivity in breast cancer assessed by the histone gamma-H2AX and 53BP1 foci. Radiat Oncol 2013;8:98. 
62. Lassmann M, Hanscheid H, Gassen D, Biko J, Meineke V, Reiners C, Scherthan H. In vivo formation of gamma-H2AX and 53BP1 DNA repair foci in blood cells after radioiodine therapy of differentiated thyroid cancer. J Nucl Med 2010;51(8):1318-25.

63. Cornelissen B, Kersemans V, Darbar S, Thompson J, Shah K, Sleeth K, Hill MA, Vallis KA. Imaging DNA damage in vivo using gammaH2AX-targeted immunoconjugates. Cancer Res 2011;71(13):4539-49.

64. Yuan SS, Lee SY, Chen G, Song M, Tomlinson GE, Lee EY. BRCA2 is required for ionizing radiation-induced assembly of Rad51 complex in vivo. Cancer Res 1999;59(15):3547-51.

65. Zhang J, Willers H, Feng Z, Ghosh JC, Kim S, Weaver DT, Chung JH, Powell SN, Xia F. Chk2 phosphorylation of BRCA1 regulates DNA double-strand break repair. Molecular \& Cellular Biology 2004;24(2):708-18.

66. Saleh-Gohari N, Bryant HE, Schultz N, Parker KM, Cassel TN, Helleday T. Spontaneous homologous recombination is induced by collapsed replication forks that are caused by endogenous DNA single-strand breaks. Mol Cell Biol 2005;25(16):7158-69.

67. Digweed M, Rothe S, Demuth I, Scholz R, Schindler D, Stumm M, Grompe M, Jordan A, Sperling K. Attenuation of the formation of DNA-repair foci containing RAD51 in Fanconi anaemia. Carcinogenesis 2002;23(7):1121-6.

68. Godthelp BC, Wiegant WW, Waisfisz Q, Medhurst AL, Arwert F, Joenje H, Zdzienicka MZ. Inducibility of nuclear Rad51 foci after DNA damage distinguishes all Fanconi anemia complementation groups from D1/BRCA2. Mutat Res 2006;594(1-2):39-48.

69. Garcia-Higuera I, Taniguchi T, Ganesan S, Meyn MS, Timmers C, Hejna J, Grompe M, D'Andrea AD. Interaction of the Fanconi anemia proteins and BRCA1 in a common pathway. Molecular Cell 2001;7(2):249-62.

70. Tebbs RS, Hinz JM, Yamada NA, Wilson JB, Salazar EP, Thomas CB, Jones IM, Jones NJ, Thompson LH. New insights into the Fanconi anemia pathway from an isogenic FancG hamster CHO mutant. DNA Repair (Amst) 2005;4(1):11-22.

71. Willers H, Kachnic LA, Luo C-M, Li L, Purschke M, Borgmann K, Held KD, Powell SN. Biomarkers and Mechanisms of FANCD2 Function. Journal of Biomedicine and Biotechnology 2008:821529.

72. Scully R, Chen J, Plug A, Xiao Y, Weaver D, Feunteun J, Ashley T, Livingston DM. Association of BRCA1 with Rad51 in mitotic and meiotic cells. Cell 1997;88(2):265-75.

73. Scully R, Chen J, Ochs RL, Keegan K, Hoekstra M, Feunteun J, Livingston DM. Dynamic changes of BRCA1 subnuclear location and phosphorylation state are initiated by DNA damage. Cell 1997;90(3):425-35. 
74. Huen MS, Sy SM, Chen J. BRCA1 and its toolbox for the maintenance of genome integrity. Nat Rev Mol Cell Biol 2010;11(2):138-48.

75. Scully R, Ganesan S, Vlasakova K, Chen J, Socolovsky M, Livingston DM. Genetic analysis of BRCA1 function in a defined tumor cell line. Molecular Cell 1999;4:1093-1099.

76. Shi W, Ma Z, Willers H, Akhtar K, Scott SP, Zhang J, Powell S, Zhang J. Disassembly of MDC1 foci is controlled by ubiquitin-proteasome-dependent degradation. $J$ Biol Chem 2008;283(46):31608-16.

77. Nakanishi K, Yang YG, Pierce AJ, Taniguchi T, Digweed M, D'Andrea AD, Wang ZQ, Jasin M. Human Fanconi anemia monoubiquitination pathway promotes homologous DNA repair. Proc Natl Acad Sci U S A 2005;102(4):1110-5.

78. Kuhnert VM, Kachnic LA, Li L, Purschke M, Gheorghiu L, Lee R, Held KD, Willers H. FANCD2deficient human fibroblasts are hypersensitive to ionising radiation at oxygen concentrations of $0 \%$ and $3 \%$ but not under normoxic conditions. Int J Radiat Biol 2009;85(6):523-31.

79. Wilson JB, Blom E, Cunningham R, Xiao Y, Kupfer GM, Jones NJ. Several tetratricopeptide repeat (TPR) motifs of FANCG are required for assembly of the BRCA2/D1-D2-G-X3 complex, FANCD2 monoubiquitylation and phleomycin resistance. Mutat Res 2010.

80. Wilson JB, Yamamoto K, Marriott AS, Hussain S, Sung P, Hoatlin ME, Mathew CG, Takata M, Thompson LH, Kupfer GM and others. FANCG promotes formation of a newly identified protein complex containing BRCA2, FANCD2 and XRCC3. Oncogene 2008;27(26):3641-52.

81. Kennedy RD, D'Andrea $A D$. DNA repair pathways in clinical practice: lessons from pediatric cancer susceptibility syndromes. J Clin Oncol 2006;24(23):3799-808.

82. Chan DW, Chen BP, Prithivirajsingh S, Kurimasa A, Story MD, Qin J, Chen DJ. Autophosphorylation of the DNA-dependent protein kinase catalytic subunit is required for rejoining of DNA double-strand breaks. Genes Dev 2002;16(18):2333-8.

83. Wang $X$, Andreassen PR, D'Andrea AD. Functional interaction of monoubiquitinated FANCD2 and BRCA2/FANCD1 in chromatin. Mol Cell Biol 2004;24(13):5850-62.

84. Tarsounas M, Davies D, West SC. BRCA2-dependent and independent formation of RAD51 nuclear foci. Oncogene 2003;22(8):1115-23.

85. Powell SN, Kachnic LA. Therapeutic exploitation of tumor cell defects in homologous recombination. Anticancer Agents Med Chem 2008;8(4):448-60.

86. Gahwiler BH, Capogna M, Debanne D, McKinney RA, Thompson SM. Organotypic slice cultures: a technique has come of age. Trends Neurosci 1997;20(10):471-7. 
87. Noraberg J, Poulsen FR, Blaabjerg M, Kristensen BW, Bonde C, Montero M, Meyer M, Gramsbergen JB, Zimmer J. Organotypic hippocampal slice cultures for studies of brain damage, neuroprotection and neurorepair. Curr Drug Targets CNS Neurol Disord 2005;4(4):435-52.

88. Merz F, Gaunitz F, Dehghani F, Renner C, Meixensberger J, Gutenberg A, Giese A, Schopow K, Hellwig C, Schafer $M$ and others. Organotypic slice cultures of human glioblastoma reveal different susceptibilities to treatments. Neuro Oncol 2013;15(6):670-81.

89. Vaira V, Fedele G, Pyne S, Fasoli E, Zadra G, Bailey D, Snyder E, Faversani A, Coggi G, Flavin $\mathrm{R}$ and others. Preclinical model of organotypic culture for pharmacodynamic profiling of human tumors. Proc Natl Acad Sci U S A 2010;107(18):8352-6.

90. Pfaffle HN, Wang M, Gheorghiu L, Ferraiolo N, Greninger P, Borgmann K, Settleman J, Benes $\mathrm{CH}$, Sequist LV, Zou L and others. EGFR-activating mutations correlate with a Fanconi anemialike cellular phenotype that includes PARP inhibitor sensitivity. Cancer Res 2013;73(20):6254-63.

91. Garcia-Villa A, Balasubramanian P, Miller BL, Lustberg MB, Ramaswamy B, Chalmers JJ. Assessment of gamma-H2AX levels in circulating tumor cells from patients receiving chemotherapy. Front Oncol 2012;2:128.

92. Kummar S, Chen A, Ji J, Zhang Y, Reid JM, Ames M, Jia L, Weil M, Speranza G, Murgo AJ and others. Phase I study of PARP inhibitor ABT-888 in combination with topotecan in adults with refractory solid tumors and lymphomas. Cancer Res 2011;71(17):5626-34.

93. Kummar S, Ji J, Morgan R, Lenz HJ, Puhalla SL, Belani CP, Gandara DR, Allen D, Kiesel B, Beumer $\mathrm{JH}$ and others. A phase I study of veliparib in combination with metronomic cyclophosphamide in adults with refractory solid tumors and lymphomas. Clin Cancer Res 2012;18(6):1726-34.

94. Wang LH, Pfister TD, Parchment RE, Kummar S, Rubinstein L, Evrard YA, Gutierrez ME, Murgo AJ, Tomaszewski JE, Doroshow JH and others. Monitoring drug-induced gammaH2AX as a pharmacodynamic biomarker in individual circulating tumor cells. Clin Cancer Res 2010;16(3):1073-84.

95. Ilie M, Hofman V, Long E, Bordone O, Selva E, Washetine K, Marquette CH, Hofman P. Current challenges for detection of circulating tumor cells and cell-free circulating nucleic acids, and their characterization in non-small cell lung carcinoma patients. What is the best blood substrate for personalized medicine? Ann Transl Med 2014;2(11):107.

96. Koch U, Krause M, Baumann M. Cancer stem cells at the crossroads of current cancer therapy failures--radiation oncology perspective. Semin Cancer Biol 2010;20(2):116-24.

97. Olive PL, Banath JP. Phosphorylation of histone $\mathrm{H} 2 \mathrm{AX}$ as a measure of radiosensitivity. Int J Radiat Oncol Biol Phys 2004;58(2):331-5. 
98. Banuelos CA, Banath JP, Kim JY, Aquino-Parsons C, Olive PL. gammaH2AX expression in tumors exposed to cisplatin and fractionated irradiation. Clin Cancer Res 2009;15(10):3344-53.

99. Olive PL, Banuelos CA, Durand RE, Kim JY, Aquino-Parsons C. Endogenous and radiationinduced expression of gammaH2AX in biopsies from patients treated for carcinoma of the uterine cervix. Radiother Oncol 2010;94(1):82-9.

100. Hoffmann TK. Systemic therapy strategies for head-neck carcinomas: Current status. GMS Curr Top Otorhinolaryngol Head Neck Surg 2012;11:Doc03.

101. Menegakis A, Eicheler W, Yaromina A, Thames HD, Krause M, Baumann M. Residual DNA double strand breaks in perfused but not in unperfused areas determine different radiosensitivity of tumours. Radiother Oncol 2011;100(1):137-44.

102. Yaromina A, Thames H, Zhou X, Hering S, Eicheler W, Dorfler A, Leichtner T, Zips D, Baumann M. Radiobiological hypoxia, histological parameters of tumour microenvironment and local tumour control after fractionated irradiation. Radiother Oncol 2010;96(1):116-22.

103. Yaromina A, Eckardt A, Zips D, Eicheler W, Schuetze C, Thames H, Baumann M. Core needle biopsies for determination of the microenvironment in individual tumours for longitudinal radiobiological studies. Radiother Oncol 2009;92(3):460-5.

104. Krause M, Yaromina A, Eicheler W, Koch U, Baumann M. Cancer stem cells: targets and potential biomarkers for radiotherapy. Clin Cancer Res 2011;17(23):7224-9.

105. Jamal M, Rath BH, Tsang PS, Camphausen K, Tofilon PJ. The brain microenvironment preferentially enhances the radioresistance of CD133(+) glioblastoma stem-like cells. Neoplasia 2012;14(2):150-8.

106. Mumbrekar KD, Fernandes DJ, Goutham HV, Sharan K, Vadhiraja BM, Satyamoorthy K, Bola Sadashiva SR. Influence of double-strand break repair on radiation therapy-induced acute skin reactions in breast cancer patients. Int J Radiat Oncol Biol Phys 2013;88(3):671-6.

107. Sak A, Grehl S, Engelhard M, Wierlemann A, Kaelberlah HP, Erichsen P, Pottgen C, Groneberg $M$, Stuschke $M$. Long-term in vivo effects of cisplatin on gamma-H2AX foci signaling in peripheral lymphocytes of tumor patients after irradiation. Clin Cancer Res 2009;15(8):2927-34.

108. Wyatt MD, Wilson DM, 3rd. Participation of DNA repair in the response to 5-fluorouracil. Cell Mol Life Sci 2009;66(5):788-99.

109. Fleckenstein J, Kuhne M, Seegmuller K, Derschang S, Melchior P, Graber S, Fricke A, Rube CE, Rube $C$. The impact of individual in vivo repair of DNA double-strand breaks on oral mucositis in adjuvant radiotherapy of head-and-neck cancer. Int J Radiat Oncol Biol Phys 2011;81(5):1465-72.

110. Liu Q, Ghosh P, Magpayo N, Testa M, Tang S, Biggs P, Paganetti H, Efstathiou JA, Lu H-M, Held KD and others. Lung Cancer Cell Line Screen Links Fanconi Anemia/BRCA Pathway Defects to 
Increased Relative Biological Effectiveness of Proton Radiation. Int J Radiat Oncol Biol Phys 2015; in press.

111. Graeser M, McCarthy A, Lord CJ, Savage K, Hills M, Salter J, Orr N, Parton M, Smith IE, ReisFilho JS and others. A marker of homologous recombination predicts pathologic complete response to neoadjuvant chemotherapy in primary breast cancer. Clin Cancer Res 2010;16(24):6159-68.

112. Shah MM, Dobbin ZC, Nowsheen S, Wielgos M, Katre AA, Alvarez RD, Konstantinopoulos PA, Yang ES, Landen CN. An ex vivo assay of XRT-induced Rad51 foci formation predicts response to PARP-inhibition in ovarian cancer. Gynecol Oncol 2014;134(2):331-7.

113. Kumareswaran R, Ludkovski O, Meng A, Sykes J, Pintilie M, Bristow RG. Chronic hypoxia compromises repair of DNA double-strand breaks to drive genetic instability. J Cell Sci 2012;125(Pt 1):189-99.

114. Bindra RS, Schaffer PJ, Meng A, Woo J, Maseide K, Roth ME, Lizardi P, Hedley DW, Bristow RG, Glazer PM. Down-regulation of Rad51 and decreased homologous recombination in hypoxic cancer cells. Mol Cell Biol 2004;24(19):8504-18.

115. Sedelnikova OA, Bonner WM. GammaH2AX in cancer cells: a potential biomarker for cancer diagnostics, prediction and recurrence. Cell Cycle 2006;5(24):2909-13.

116. Wu J, Clingen PH, Spanswick VJ, Mellinas-Gomez M, Meyer T, Puzanov I, Jodrell D, Hochhauser D, Hartley JA. gamma-H2AX foci formation as a pharmacodynamic marker of DNA damage produced by DNA cross-linking agents: results from 2 phase I clinical trials of SJG-136 (SG2000). Clin Cancer Res 2013;19(3):721-30.

117. Park JW, Nickel KP, Torres AD, Lee D, Lambert PF, Kimple RJ. Human papillomavirus type 16 E7 oncoprotein causes a delay in repair of DNA damage. Radiother Oncol 2014;113(3):337-44.

118. Rieckmann T, Tribius S, Grob TJ, Meyer F, Busch CJ, Petersen C, Dikomey E, Kriegs M. HNSCC cell lines positive for HPV and p16 possess higher cellular radiosensitivity due to an impaired DSB repair capacity. Radiother Oncol 2013;107(2):242-6.

119. Lohaus F, Linge A, Tinhofer I, Budach V, Gkika E, Stuschke M, Balermpas P, Rodel C, Avlar M, Grosu AL and others. HPV16 DNA status is a strong prognosticator of loco-regional control after postoperative radiochemotherapy of locally advanced oropharyngeal carcinoma: Results from a multicentre explorative study of the German Cancer Consortium Radiation Oncology Group (DKTK-ROG). Radiother Oncol 2014;113(3):317-23.

120. Bhogal N, Jalali F, Bristow RG. Microscopic imaging of DNA repair foci in irradiated normal tissues. Int J Radiat Biol 2009:1-15. 
121. Redon CE, Weyemi U, Parekh PR, Huang D, Burrell AS, Bonner WM. gamma-H2AX and other histone post-translational modifications in the clinic. Biochim Biophys Acta 2012;1819(7):743-56.

122. Sak A, Grehl S, Erichsen P, Engelhard M, Grannass A, Levegrun S, Pottgen C, Groneberg M, Stuschke M. gamma-H2AX foci formation in peripheral blood lymphocytes of tumor patients after local radiotherapy to different sites of the body: dependence on the dose-distribution, irradiated site and time from start of treatment. Int J Radiat Biol 2007;83(10):639-52.

123. Goutham HV, Mumbrekar KD, Vadhiraja BM, Fernandes DJ, Sharan K, Kanive Parashiva G, Kapaettu S, Bola Sadashiva SR. DNA double-strand break analysis by gamma-H2AX foci: a useful method for determining the overreactors to radiation-induced acute reactions among headand-neck cancer patients. Int J Radiat Oncol Biol Phys 2013;84(5):e607-12.

124. Rübe CE, Fricke A, Schneider R, Simon K, Kuhne M, Fleckenstein J, Graber S, Graf N, Rübe C. DNA repair alterations in children with pediatric malignancies: novel opportunities to identify patients at risk for high-grade toxicities. Int J Radiat Oncol Biol Phys 2010;78(2):359-69.

125. Schuler N, Palm J, Kaiser M, Betten D, Furtwangler R, Rübe C, Graf N, Rübe CE. DNA-damage foci to detect and characterize DNA repair alterations in children treated for pediatric malignancies. PLoS One 2014;9(3):e91319.

126. van Oorschot B, Hovingh SE, Moerland PD, Medema JP, Stalpers LJ, Vrieling H, Franken NA. Reduced activity of double-strand break repair genes in prostate cancer patients with late normal tissue radiation toxicity. Int J Radiat Oncol Biol Phys 2014;88(3):664-70.

127. Brzozowska K, Pinkawa M, Eble MJ, Muller WU, Wojcik A, Kriehuber R, Schmitz S. In vivo versus in vitro individual radiosensitivity analysed in healthy donors and in prostate cancer patients with and without severe side effects after radiotherapy. Int J Radiat Biol 2012;88(5):405-13.

128. Werbrouck J, Duprez F, De Neve W, Thierens H. Lack of a correlation between gammaH2AX foci kinetics in lymphocytes and the severity of acute normal tissue reactions during IMRT treatment for head and neck cancer. Int J Radiat Biol 2011;87(1):46-56.

129. Liu Q, Wang M, Kern AM, Khaled S, Han J, Yeap BY, Hong TS, Settleman J, Benes CH, Held KD and others. Adapting a Drug Screening Platform to Discover Associations of Molecular Targeted Radiosensitizers with Genomic Biomarkers. Mol Cancer Res 2014;submitted. 


\section{Figure Legends}

Figure 1 Examples of DNA damage response (DDR) foci assessment in human cancer tissues and cells. A) Representative immunofluorescence microscopy images (100x) investigating the DDR of patient-derived lung cancer tissues treated with ionizing radiation (IR) or cisplatin ex-vivo ${ }^{4}$. B) Correlation of clonogenic survival fraction at $2 \mathrm{~Gy}$ with the percentage of cells displaying at least $10 \gamma$ H2AX foci 24 hours (h) after 2 Gy irradiation for 18 non-small cell lung carcinoma (NSCLC) cell lines. The number of foci at baseline is subtracted. Results of a linear regression analysis are shown (Willers et al., unpublished). C) Left panel, representative microscopy images illustrating the increase in residual $\gamma-\mathrm{H} 2 \mathrm{AX}$ foci $24 \mathrm{~h}$ after irradiation with 6 Gy plus the HSP90 inhibitor (i) 17-AAG at $20 \mathrm{nM}$ compared to IR alone. Right panel, fraction of head and neck squamous cell cancer (HNSCC) cells with at least 20 $\gamma-\mathrm{H} 2 \mathrm{AX}$ foci after treatment with IR with or without 17-AAG (Liu et al., unpublished). D) Radiosensitization factor for 2 Gy IR +/- 17-AAG using a previous IR/drug screening approach ${ }^{129}$. E) Representative images illustrating the persistence of 53BP1 foci following ex-vivo irradiation of tumor tissues from a bladder cancer patient. F) Immunohistochemistry and immunofluorescence images of consecutive sections of a HNSCC patient sample. Panel a, Differential staining with haematoxylin/eosin for tumor cell identification; Panel b, Definition of tumor oxygenation status: hypoxia marker pimonidazole in dark red cytoplasmic stain, marked with white asterisk. Definition of cell viability: proliferation marker BrdU in brown nuclear stain, marked with black arrows. Tissue is counterstained with hematoxylin. Box indicates position of panel c; Panel c, Unexposed control sample with high background level of $\gamma-\mathrm{H} 2 \mathrm{AX}$ foci in green. DNA is stained with DAPI in blue. Scale bar and original

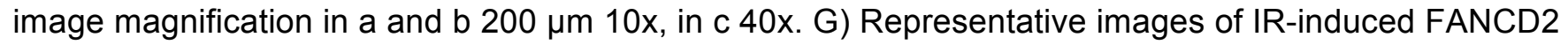
foci in only $5 \%$ of cells in a tissue sample from a lung cancer patient ${ }^{4}$. 
Figure 2 Importance of DNA damage-induced foci formation. A) RAD51 protein expression by Western blot (upper image) and nuclear staining using immunofluorescence microscopy (lower images) in two breast cancer cell lines, MDA-MB-436 cells with no BRCA1 expression due to mutation and HCC1937 cells, which also have a BRCA1 mutation but express a protein with residual function. MMC, mitomycin C. (Willers et al., unpublished). B) Clonogenic survival fractions following MMC treatment at the indicated concentrations for 1 hour. C) Schematic illustrating how defects in the BRCA/Fanconi Anemia (FA) pathway could be identified through monitoring of foci responses.

Figure 3 Principle of ex-vivo foci assay. See text for details. IF, immunofluorescence; H\&E, hematoxylin and eosin stain; IHC, immunohistochemistry

Figure 4 Penetration of drug into tumor tissue and heterogeneity of RAD51 foci response. A) Example of RAD51 foci responses 5 hours after exposure of breast cancer tissues to cisplatin $(8 \mu \mathrm{M})$ or ionizing radiation (IR) (10 Gy). Cells with at least two foci were scored as positive. Horizontal lines represent the median (Willers et al., unpublished). B) Analogous to panel A, example of RAD51 foci responses 5 hours after exposure of lung cancer tissues to cisplatin $(8 \mu \mathrm{M})$. Data points represent foci counts from random high-power images ${ }^{4}$. 
Figure 1

Figure 1 ( 2 columns)

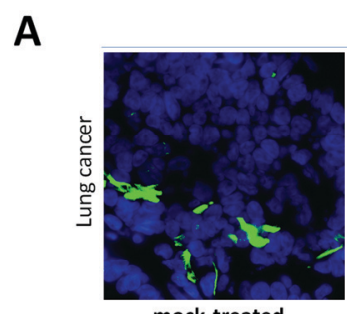

mock-treated

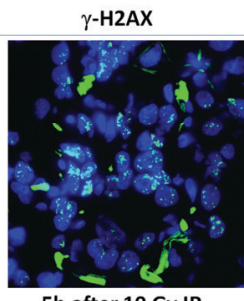

5 h after 10 Gy IR

C

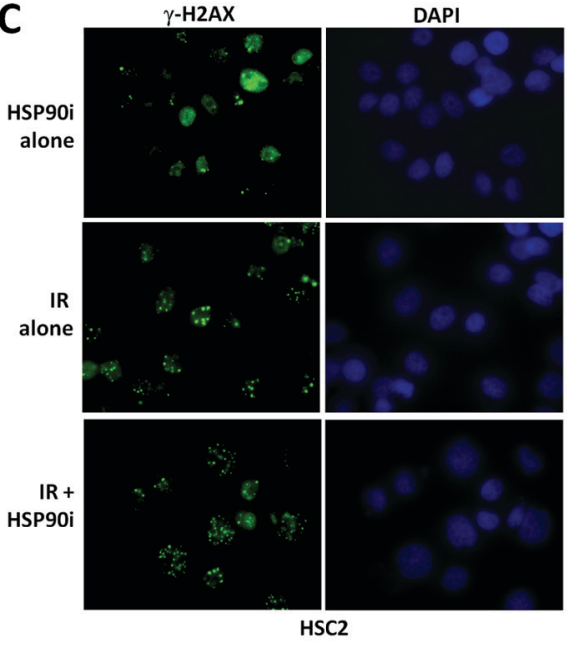

$\mathbf{F}$

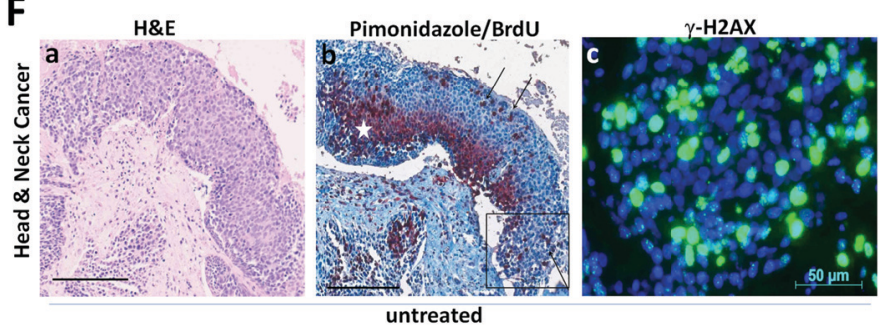

B NSCLC Cancer Cell Lines

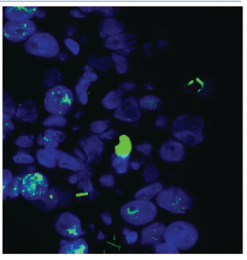

$5 \mathrm{~h}$ cisplatin at $8 \mu \mathrm{M}$
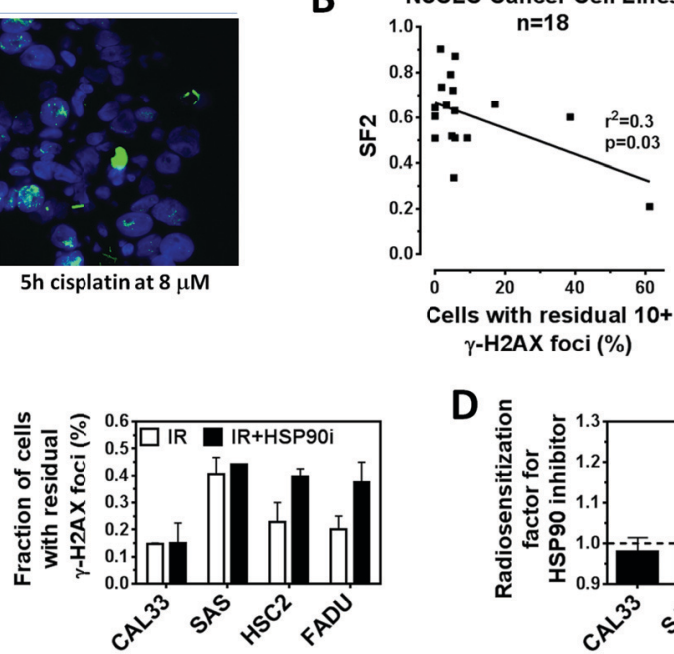
\begin{tabular}{llll}
\hline 0 & 20 & 40 & 60 \\
Cells & with residual & $10+$
\end{tabular} $\gamma$-H2AX foci (\%)

D

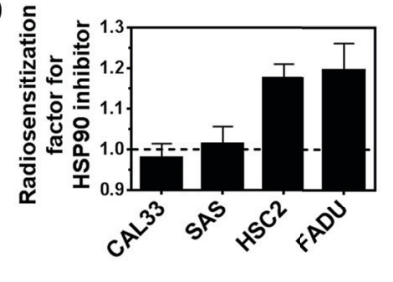

E

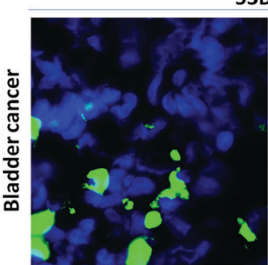

mock-treated

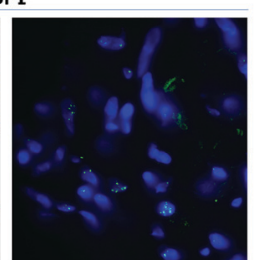

24h after 10 Gy IR

G

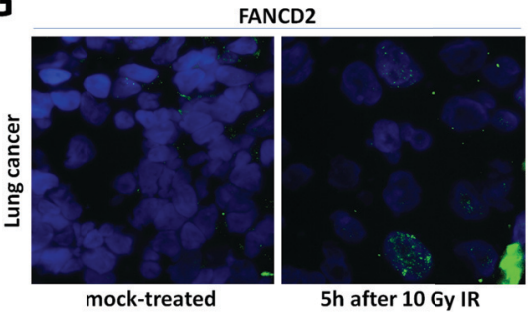


Figure 2

Figure 2 ( 1.5 columns)

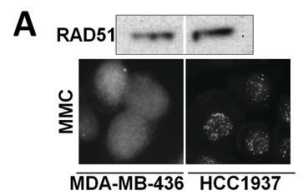

B

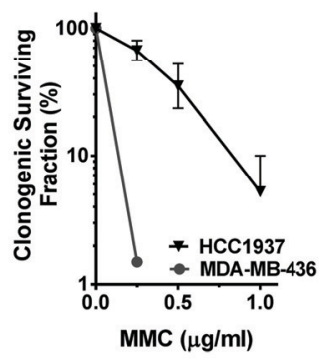

C

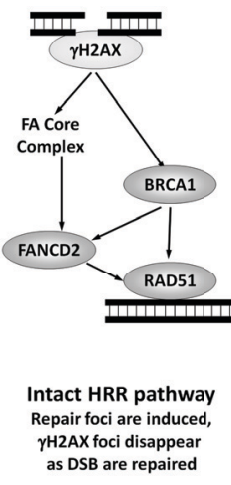

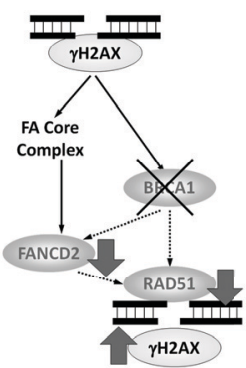

Disrupted HRR pathway Example: reduced BRCA1 $\rightarrow$ reduced FANCD2, RAD51 foc $\rightarrow$ persistent $\gamma \mathrm{H} 2 \mathrm{AX}$ 
Figure 3

Figure 3 ( 1.5 columns)

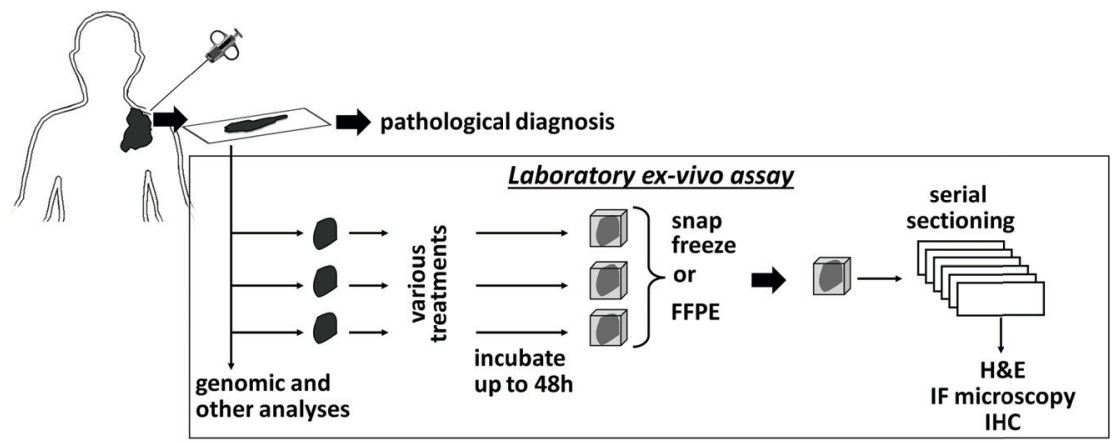


Figure 4

A

Figure 4 ( 1 column)

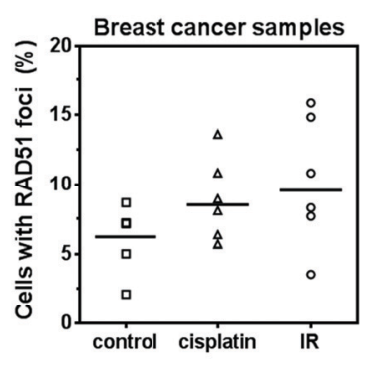

B

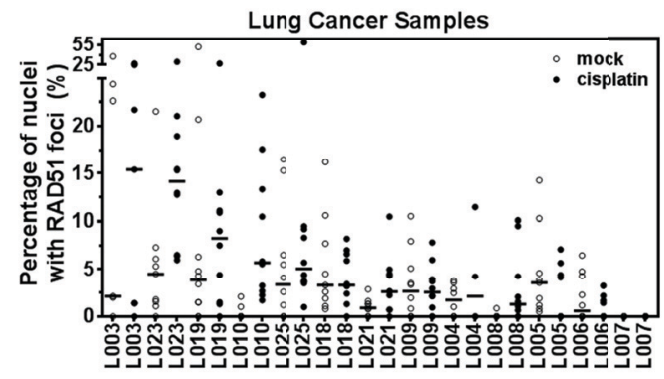


Table 1. Examples of radiosensitization by molecular targeted agents correlating with increased number of residual DSB

\begin{tabular}{|c|c|c|c|c|c|c|}
\hline Target & Drug & $\mathbf{I R}$ & $y-\mathrm{H} 2 \mathrm{AX}$ & 53BP1 & Cancer cell lines & Reference (no.) \\
\hline AKT & API-59CJ-OH & $1-5 \mathrm{~Gy}$ & $\mathrm{X}$ & & A549, H460 (NSCLC) & Toulany et al. 2008 (32) \\
\hline AMPK & Metformin & $6 \mathrm{~Gy}$ & $\mathrm{x}$ & & MiaPaCa-2, Panc1 (PDAC) & Fasih et al. 2014 (33) \\
\hline ATR & VE-822 & $6 \mathrm{~Gy}$ & $\mathrm{x}$ & $\mathrm{X}$ & MiaPaCa-2 (PDAC) & Fokas et al. 2012 (34) \\
\hline EGFR & $\begin{array}{l}\text { Erlotinib } \\
\text { Erlotinib \& cetuximab }\end{array}$ & $\begin{array}{l}2 \mathrm{~Gy} \\
8 \mathrm{~Gy}\end{array}$ & $\begin{array}{l}x \\
x\end{array}$ & $\mathrm{x}$ & $\begin{array}{l}\text { A549, H1299 (NSCLC) } \\
\text { multiple NSCLC cell lines }\end{array}$ & $\begin{array}{l}\text { Myllynen et al. } 2011 \text { (35) } \\
\text { Wang et al. } 2011 \text { (36) }\end{array}$ \\
\hline HDAC & $\begin{array}{l}\text { NDACI054 } \\
\text { MS- } 275\end{array}$ & $\begin{array}{l}6 \mathrm{~Gy} \\
5 \mathrm{~Gy}\end{array}$ & $\begin{array}{l}x \\
X\end{array}$ & $\mathrm{x}$ & $\begin{array}{l}\text { A549 (NSCLC) } \\
\text { U251 (GBM), DU145 (Prostate Ca) }\end{array}$ & $\begin{array}{l}\text { Hehlgans et al. } 2013 \text { (37) } \\
\text { Camphausen et al. } 2004 \text { (38) }\end{array}$ \\
\hline HER2 & Trastuzumab & $4 \mathrm{~Gy}$ & $\mathrm{x}$ & & A549, H661 (NSCLC) & Toulany et al. 2010 (39) \\
\hline HSP90 & $\begin{array}{l}\text { 17-DMAG } \\
\text { PU-H71 }\end{array}$ & $\begin{array}{l}2 \mathrm{~Gy} \\
5 \mathrm{~Gy}\end{array}$ & $\begin{array}{l}X \\
X\end{array}$ & & $\begin{array}{l}\text { MiaPaCa-2, ASPC1 (PDAC) } \\
\text { A549 (NSCLC) }\end{array}$ & $\begin{array}{l}\text { Dote et al. } 2006(40) \\
\text { Segawa et al. } 2014 \text { (41) }\end{array}$ \\
\hline IGF1R & CP-751,871 & $10 \mathrm{~Gy}$ & $\mathrm{x}$ & & H460 (NSCLC) & Iwasa et al. 2009 (42) \\
\hline MEK & PD98059 & $2 \mathrm{~Gy}$ & $\mathrm{x}$ & & A549 (NSCLC) & Kriegs et al. 2010 (43) \\
\hline MET & MP470 & $4 \mathrm{~Gy}$ & $\mathrm{x}$ & & multiple GBM cell lines & Welsh et al. 2009 (44) \\
\hline mTOR & $\begin{array}{c}\text { INK128 } \\
\text { Rapamycin \& RAD001 }\end{array}$ & $\begin{array}{l}2 \mathrm{~Gy} \\
8 \mathrm{~Gy}\end{array}$ & $\begin{array}{l}x \\
X\end{array}$ & & $\begin{array}{l}\text { PSN1 (PDAC) } \\
\text { MCF7 (Breast Ca) }\end{array}$ & $\begin{array}{l}\text { Hayman et al. } 2014 \text { (45) } \\
\text { Chen et al. } 2011 \text { (46) }\end{array}$ \\
\hline PARP & ABT-888 & $4 \mathrm{~Gy}$ & $\mathrm{x}$ & & HCT116 (CRC) & Shelton et al. 2013 (47) \\
\hline PI3K & BEZ235 & 4 Gy & $\mathrm{X}$ & & FaDu (HNSCC) & Fokas et al. 2012 (48) \\
\hline & LY294002 & $4 \mathrm{~Gy}$ & $x$ & & U251 (GBM) & Kao et al. 2007 (49) \\
\hline SRC & Dasatinib & $4 \mathrm{~Gy}$ & $\mathrm{x}$ & $\mathrm{x}$ & multiple HNSCC cell lines & Raju et al. 2012 (50) \\
\hline STAT3 & NSC74859 & $1 \mathrm{~Gy}$ & $\mathrm{x}$ & & ECA109, TE13 (ESCC) & Zhang et al. 2014 (51) \\
\hline TGF $\beta R I$ & LY2109761 & 2 Gy & $\mathrm{x}$ & & U87MG (GBM) & Zhang et al. 2011 (52) \\
\hline WEE-1 & PD0166285 & $4 \mathrm{~Gy}$ & $\mathrm{X}$ & & several osteosarcoma cell lines & PosthumaDeBoer et al. 2011 (53) \\
\hline
\end{tabular}

Ca, carcinoma; ESCC, esophageal squamous cell cancer; GBM, glioblastoma multiforme; HNSCC, head and neck squamous cell carcinoma;

NSCLC, non-small cell lung carcinoma; PDAC, pancreatic duct adenocarcinoma 